\title{
Synergic Topological- and Size-Control on Phosphazane Chemistry: First Unfolded Hybrid Tetrameric Macrocycle
}

\author{
Ying Sim,,$^{[a], \dagger}$ Felix Leon, ${ }^{[a], \dagger}$ Rakesh Ganguly, ${ }^{[a, b]}$ Jesús Díaz, ${ }^{[c] *}$ Jack K. Clegg, ${ }^{[\mathrm{d}] \star}$ Felipe García ${ }^{[\mathrm{a}] *}$
}

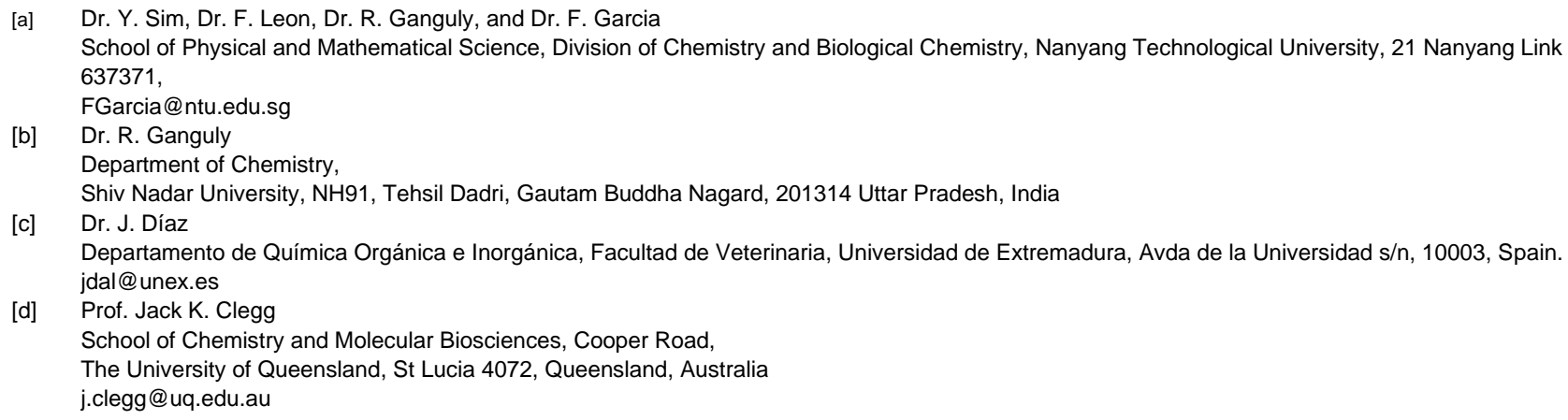

\begin{abstract}
Inorganic macrocycles remain as challenging synthetic targets due to limited number of strategies reported for their syntheses. Among these species, cyclodiphosphazane macrocycles have been recently highlighted as promising candidates for supramolecular chemistry. However, their further implementation has been handicapped by the lack of synthetic routes to large high-order cyclodiphosphazane macrocycles. In the case of hybrid organicinorganic macrocycles, their size and topological arrangement - folded vs unfolded (i.e., exo/endo vs. exo/exo) - is determined by the geometry of the linker used, which renders the synthesis of differently sized and topologically arranged macrocycles into a tedious screening process. In the particular case of asymmetric bifunctional organic linkers, all previously reported species produce small dimeric exo/endo macrocycles. Whereas symmetric linkers have shown to give rise to a handful of larger than dimeric macrocycles, these species display a folded topology as a result of the exo/endo arrangement of the linkers within the backbone. However, rational and simultaneous selection over their topology and size has never been achieved. Herein, we report an unprecedented combination of prearranged building blocks and a multi-step synthetic route to rationally and simultaneously enable access to an unfolded tetrameric macrocycle, which is not accessible using conventional synthetic strategies. The obtained macrocycle, cis- $\left[\mu-\mathrm{P}\left(\mu-\mathrm{N}^{\mathrm{t}} \mathrm{Bu}\right)\right]_{2}(\mu-\mathrm{p}-$ $\left.\left.\mathrm{OC}_{6} \mathrm{H}_{4} \mathrm{C}(\mathrm{O}) \mathrm{O}\right)\right]_{4}\left[\mu-\mathrm{P}\left(\mu-\mathrm{N}^{\prime} \mathrm{Bu}\right)\right]_{2}(4)$, is the first unfolded open-face hybrid cyclodiphosphazane macrocycle reported and displays a cavity area of $110.1 \AA^{2}$ - the largest of its kind.
\end{abstract}

\section{Introduction}

Organic macrocycles represent have been attractive synthetic targets due to their numerous applications. ${ }^{[1-4]}$ In this context, cyclodiphosphazane-based inorganic macrocycles have drawn attention due to both their promise in host guest chemistry and anion sensing. ${ }^{[5-14]}$ Cyclophosphazane species have been widely explored over the past decades due to their chemical versatility, ${ }^{[15]}$ action as excellent neutral and/or anionic ligands for metal coordination $^{[16-23]}$ and building blocks for the construction of larger molecules, as well as utility in biological applications and supramolecular chemistry. ${ }^{[12,13,24-32]}$

Depending on the nature of the bifunctional linkers employed, their reaction with dichlorocyclodiphosphazane, $\left[\mathrm{CIP}\left(\mu-\mathrm{N}^{\mathrm{t} B u}\right)\right]_{2}(\mathbf{1})$,

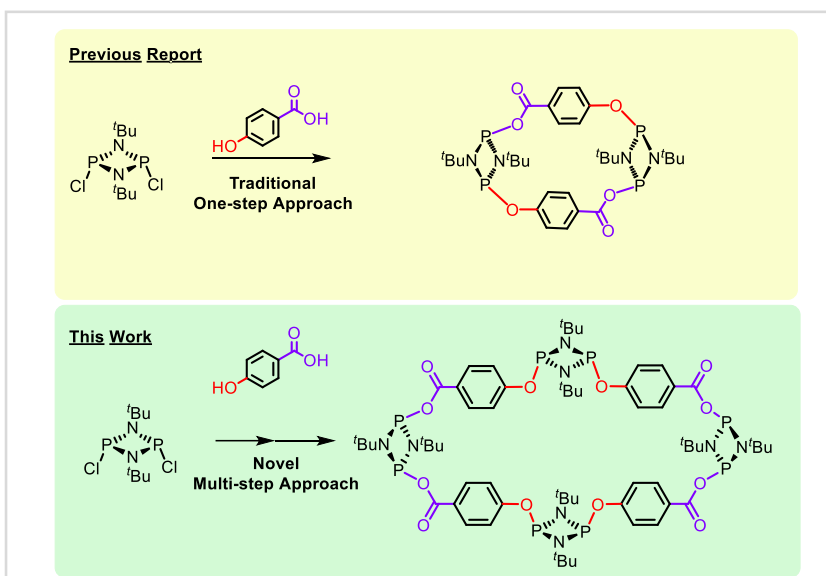

Figure 1. Schematic illustration of the traditional one-step and the herein reported novel multi-step synthetic strategy.

yields differently-sized fully inorganic or hybrid macrocycles. In this context, over the past two decades there has been particularinterest in the area of hybrid $\mathrm{PIII}_{2} \mathrm{~N}_{2}$ macrocycles due to their dual inorganic-organic nature.

Generally, the formation of hybrid cyclic derivatives are performed in a one-step synthetic approach using an equimolar amount of reactants (i.e., cyclophaphazane and organic linker) in the presence of excess triethylamine. ${ }^{[33-38]}$ The size of the macrocyclic products formed (e.g., di-, tri- and tetrameric species) however is strictly determined by the nature of the bifunctional linkers employed and governed by the most thermodynamic products. ${ }^{[33,34,39]}$

Within the hybrid phosphazane macrocyclic family there is a large number of reported examples of condensation reactions comprising symmetric bifunctional organic linkers $(\mathbf{L}-\mathbf{L})$ to produce hybrid inorganic-organic macrocycles of general formula $\left[(\mu-\mathrm{L}-\mathrm{L}) \mathrm{P}\left(\mu-\mathrm{N}^{t} \mathrm{Bu}\right)\right]_{\mathrm{n}}{ }^{[31,32,34,38]}$ Among these species, the majority are dimeric species $(n=2){ }^{[31,32,34]}$ In the case of trimeric $\mathrm{P}^{\mathrm{III}}{ }_{2} \mathrm{~N}_{2}$ macrocycles $(n=3)$, only two examples have been isolated and fully characterised. ${ }^{[34,39]}$ Large folded tetrameric macrocycles ( $n=$ 4) have only been obtained from 1,4-diaminobenzene in moderate yields, ${ }^{[40]}$ and with resorcinol as a minor product. ${ }^{[3]}$

One would expect that reactions involving asymmetric bifunctional organic linkers (L-L') would provide certain degree of 


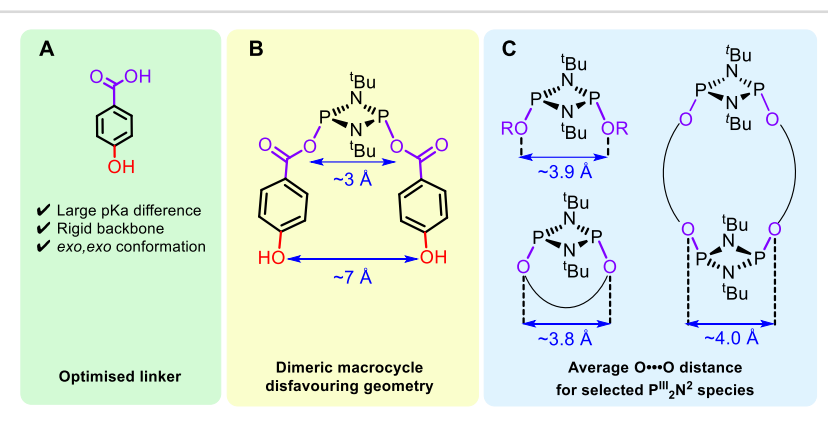

Figure 2. Bifunctional selection criteria: (a) linker prerequires, (b) dimeric $\mathrm{P}_{2} \mathrm{~N}_{2}$ macrocycle disfavouring geometry building block, and (c) previously reported $\mathrm{O} \cdots \mathrm{O}$ distances on previously reported cyclic and acyclic $\mathrm{P}^{\mathrm{III}}{ }_{2} \mathrm{~N}_{2}$ species.

control over the $\mathrm{PIII}_{2} \mathrm{~N}_{2}$ macrocyclic outcome due to the differential chemical properties between the inequivalent terminal moieties. However, these species have been exclusively isolated as small dimeric $\mathrm{P}^{\mathrm{III}}{ }_{2} \mathrm{~N}_{2}$ species of the type $\left[\left(\mu-\mathrm{L}-\mathrm{L}^{\prime}\right) \mathrm{P}\left(\mu-\mathrm{N}^{\mathrm{t}} \mathrm{Bu}\right)\right]_{2}$ displaying both cis and trans arrangements. ${ }^{[35,38]}$

To date, despite the tremendous efforts invested over the last two decades in the synthesis of these species, no synthetic routes capable of controlling the size of hybrid $\mathrm{P}^{\mathrm{III}}{ }_{2} \mathrm{~N}_{2}$ macrocycles have been reported. Hence, the development of new methodologies capable of rationally controlling to the end $\mathrm{P} \mathrm{II}_{2} \mathrm{~N}_{2}$ macrocyclic product is key to the advancement of the field.

Since traditional one-step equimolar approaches have repeatedly proven inadequate to access larger than dimeric phosphazane frameworks and/or enable control over macrocycle size (and topology), we postulated the differential properties present in asymmetric linkers, in combination with elaborate multistep routes, can be capitalised on to obtain species otherwise not accessible via conventional synthetic routes.

As a proof-of-concept, we herein describe the selective synthesis of the largest reported hybrid inorganic-organic $\mathrm{PIII}_{2} \mathrm{~N}_{2}$ macrocycle via the synergic combination of "pre-arranged" $\mathrm{P}^{\mathrm{III}} \mathrm{N}_{2}$ building blocks, and an elaborated multi-step synthetic route. This approach is in stark contrast to the previously described traditional single-step synthetic route, which only affords small dimeric macrocyclic species (Figure 1).

\section{Results and discussion}

Bifunctional organic linker requisites and linker selection Initially, we reasoned that the differential chemical and reactivity properties present in asymmetric linkers could be leveraged on for the synthesis of a cis-"pre-arranged" building block, which in turn would grant access to large cis hybrid inorganic-organic phosphazane macrocycles comprising asymmetric linkers.

For this purpose, we hypothesised that an ideal linker would require: (i) the presence of two functionalities with pronounced $\mathrm{pK}_{\mathrm{a}}$ differences, (ii) a rigid backbone with an appropriate substitution pattern, and (iii) a strong preference for an exo,exo conformation upon reaction with $\mathrm{P}_{2} \mathrm{~N}_{2}$ (to enforce unfolded topologies).

After in depth review of the literature and exhaustive analysis of the previously published work on $\mathrm{P}_{2}{ }_{2} \mathrm{~N}_{2}$ macrocycles, we selected 4-hydroxybenzoic acid as the optimal organic linker for the following reasons (see Figure 2).

Firstly, this compound compromises two acidic moieties - i.e., $\mathrm{COOH}$ and $-\mathrm{OH}$ with $\mathrm{pK}_{\mathrm{a}} \mathrm{s} \sim 4.20$ and $\sim 10$, respectively - bonded to a rigid phenyl group in a para conformation - prerequisites (i) and (ii), respectively. In addition, all previously reported cyclodiphosphazane species containing $-\mathrm{O}(\mathrm{O}) \mathrm{C}-\mathrm{X}(\mathrm{X}=\mathrm{Ph}-\mathrm{O}-$-, $\mathrm{Ph}-$ $\mathrm{CN},-\mathrm{C}(\mathrm{O}) \mathrm{O}-$, and $\mathrm{CF}_{3}$ ) moieties directly bonded to the $\mathrm{P}_{2}{ }_{2} \mathrm{~N}_{2}$ ring exhibit a strong preference for exo,exo conformation ${ }^{[35,41]}$. prerequisite (iii) - which is in contrast with commonly reported hydroxyl and amino groups (Figure 2a). ${ }^{[38,42-44]}$

Secondly, in the previously reported $\mathrm{P}^{\mathrm{III}}{ }_{2} \mathrm{~N}_{2}$ exo,exo monomer containing two $-\mathrm{OC}(\mathrm{O}) \mathrm{PhCN}$ substituents, the distances between the distal para substituents is greater than the average distance between $\mathrm{P}^{\mathrm{III}}{ }_{2} \mathrm{~N}_{2}$ substituents (Figure 2b). This topological arrangement creates a geometrical mismatch that we envisage will disfavour the formation of small dimeric $\mathrm{P}^{\mathrm{III}}{ }_{2} \mathrm{~N}_{2}$ macrocycles (Figure 2c shows the average $\mathrm{O} \cdots \mathrm{O}$ distance for cyclic and acyclic $\mathrm{PIII}_{2} \mathrm{~N}_{2}$ species containing organic substituents or linkers).

Lastly, this linker has been previously reported to produce a trans dimeric macrocycle, trans $-\left[\left(\mu-\mathrm{O}-\mathrm{C}_{6} \mathrm{H}_{4}-\mathrm{COO}\right) \mathrm{P}\left(\mu-\mathrm{N} \mathrm{Bu}^{\prime}\right)\right]_{2}(\mathbf{2 a})$, as sole product when conventional equimolar single-step synthetic route was used (Scheme 1). ${ }^{[35]}$ This selectivity for dimeric macrocycles will serve a base model and benchmark in our proof-of-concept studies (Scheme 1, left).

\section{Synthesis of cis "pre-arranged" building block}

With this in mind, we set out to synthesise the targeted $\mathrm{PII}_{2} \mathrm{~N}_{2}$ building block comprising two - $\mathrm{OC}(\mathrm{O}) \mathrm{PhOH}$ substituents. Compound 1 was reacted with two equivalences of 4hydroxybenzoic acid in THF at $-78^{\circ} \mathrm{C}$ in the presence of base (i.e. $\mathrm{Et}_{3} \mathrm{~N}$ ) and the resulting mixture was left to gradually warm up to room temperature and further stirred for 3 hours. The in situ ${ }^{31} \mathrm{P}$ $\left\{{ }^{1} \mathrm{H}\right\}$ NMR spectra - shown in Figure 3, top - revealed a singlet resonance signal at $\delta 172.5 \mathrm{ppm}$, which was attributed to the acyclic cis di-substituted monomeric building block, $\left[\left(\mathrm{HOC}_{6} \mathrm{H}_{4}(\mathrm{O}) \mathrm{CO}\right) \mathrm{P}\left(\mu-\mathrm{N}^{t} \mathrm{Bu}\right)\right]_{2}$ (2a, in Scheme 1) (cf. previously reported $\left.\left[(\mathrm{CN}) \mathrm{C}_{6} \mathrm{H}_{4}(\mathrm{O}) \mathrm{CO}\right) \mathrm{P}\left(\mu-\mathrm{N}^{t} \mathrm{Bu}\right)\right]_{2}$ counterpart $\delta 173.0$ ppm). ${ }^{[35]}$ Furthermore, there were no resonances recorded consistent with the formation of the aryl oxide cis di-substituted derivative $\left[\left(\mathrm{HOC}(\mathrm{O}) \mathrm{C}_{6} \mathrm{H}_{4} \mathrm{O}\right) \mathrm{P}\left(\mu-\mathrm{N}^{t} \mathrm{Bu}\right)\right]_{2}(\mathbf{2 b}$, in Scheme 1), since no signals were observed at $\delta \sim 144 \mathrm{ppm}$ - where cis acyclic alkoxide or aryloxide species would have been expected.[11-33] Additionally, neither signals for the trans di-substituted (2c, in Scheme 1) monomer (i.e., mixed aryl oxide and alkoxide), nor the previously reported trans dimeric macrocycle (3a, Figure $\mathbf{3}$ bottom) were observed. Unfortunately, attempts to isolate analytically pure samples of $\mathbf{2 a}$ were unsuccessful. Hence, the cis pre-arranged building block 2a was used in situ throughout our studies.

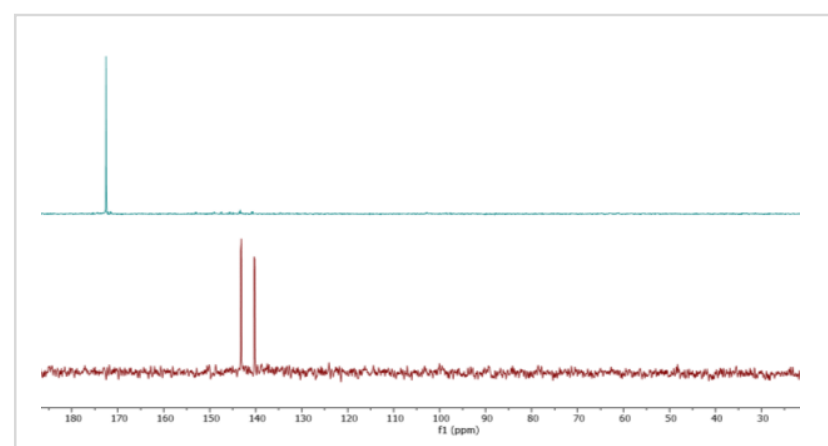

Figure 3. In situ ${ }^{31} \mathrm{P}-\left\{{ }^{1} \mathrm{H}\right\}$ NMR spectra of conventional one-step approach reaction leading to $\mathbf{3 a}$ (bottom) and step 1 the multi-step synthetic route leading to $\mathbf{2 a}$ (top). 


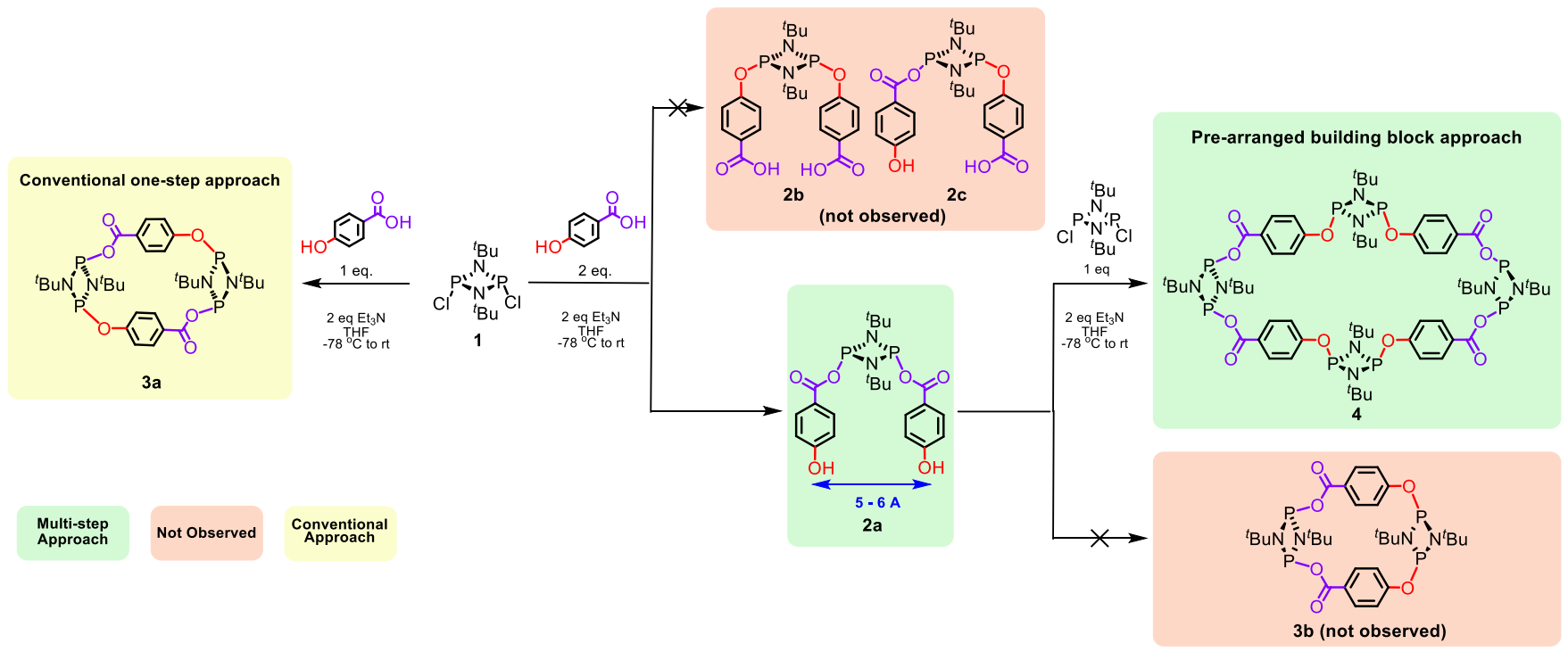

Scheme 1. Reaction scheme for the multi-step methodology to macrocycle 4.

\section{Synthesis of all cis hybrid $\mathrm{PIII}_{2} \mathrm{~N}_{2}$ macrocycle}

After the successful formation of the targeted cis pre-arranged building block, 2a was subsequently reacted with compound 1 in the presence of $\mathrm{Et}_{3} \mathrm{~N}$ at $-78{ }^{\circ} \mathrm{C}$ and left to stir overnight (Scheme 1, right). The in situ ${ }^{31} \mathrm{P}\left\{{ }^{1} \mathrm{H}\right\} \mathrm{NMR}$ spectra recorded revealed two singlet resonance signals at $\delta 180.0$ and $150.1 \mathrm{ppm}$ along with small resonance signals corresponding to the dimeric trans macrocycle $\mathbf{3 a}$, presumably due to fragmentation and rearrangement products of $\mathbf{2 a}$ or its derivatives (see Figure S2) ${ }^{\left[{ }^{[0,34]}\right.}$ Despite these minor side product, pure compound $\mathbf{4}$ was isolated in good yields by filtration of the reaction crude in hexanes. High-quality crystals, suitable for SC-XRD, were obtained by cooling down a concentrated solution of $\mathbf{4}$ in hexanes. These studies indicated the successful formation of an all-cis tetrameric macrocycle obtained $-c i s-\left[\mu-\mathrm{P}\left(\mu-\mathrm{N}^{\prime} \mathrm{Bu}\right)\right]_{2}(\mu-p-$ $\left.\left.\mathrm{OC}_{6} \mathrm{H}_{4} \mathrm{C}(\mathrm{O}) \mathrm{O}\right)\right]_{4}\left[\mu-\mathrm{P}\left(\mu-\mathrm{N}^{\mathrm{t} B u}\right)\right]_{2}(4)$, in contrast to the dimeric macrocycle obtained using conventional one-step equimolar synthetic routes (see Figure 4).

Notably, since the selected linker imposes an exo,exo around the $-\mathrm{C}(\mathrm{O}) \mathrm{O}$ - moiety, compound $\mathbf{4}$ features an unfolded topology which leads to the largest cavity among the hybrid inorganicorganic cyclodiphosphazane macrocyclic family to date. This uniquely large ellipsoidal cavity displays two orthogonal axes of 19.36 $\AA$ and $7.24 \AA$, and an area of $110.1 \AA^{2}$ which significantly larger any previously reported hybrid $\mathrm{PIII}_{2} \mathrm{~N}_{2}$-macrocycles (Table S1). Moreover, this large cavity enables partial rotation of central $\mathrm{P}^{\mathrm{III}} \mathrm{N}_{2}$ bonded to hydroxyl groups, which is illustrated by the presence of two different macrocyclic conformers within the crystal lattice, which results in significant disorder in the diffraction data collected (Figure 4). In one conformer, the two opposite $\mathrm{P}^{\mathrm{III}} \mathrm{N}_{2}$ units are parallel to each other while in the other conformer, these $\mathrm{P}_{2} \mathrm{~N}_{2}$ units are almost perpendicular (Figure S10). To the best of our knowledge, the observed ability of the central $\mathrm{P}^{\mathrm{II}}{ }_{2} \mathrm{~N}_{2}$ units to partially rotate has never been observed in any cyclodiphosphazane macrocyclic species reported.

The relative mobility of the central $\mathrm{P}_{2} \mathrm{~N}_{2}$ units around the hydroxyl axis in $\mathbf{4}$ is further confirmed by ${ }^{1} \mathrm{H}$ NMR spectroscopy, where all the tert-butyl groups display a singlet resonance at $\delta$ $1.39 \mathrm{ppm}$ and which split into two different environments upon cooling at $5^{\circ} \mathrm{C}$ (see Figure S7).

\section{Mechanism of formation and computational studies}

Notably, the $0 \cdots O$ bond distances in $\mathbf{4}$ provides geometrical clues to rationalise the observed preference for the formation of (a)

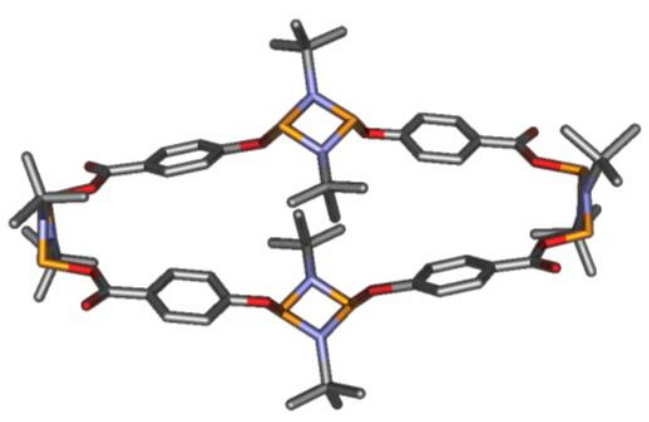

(b)

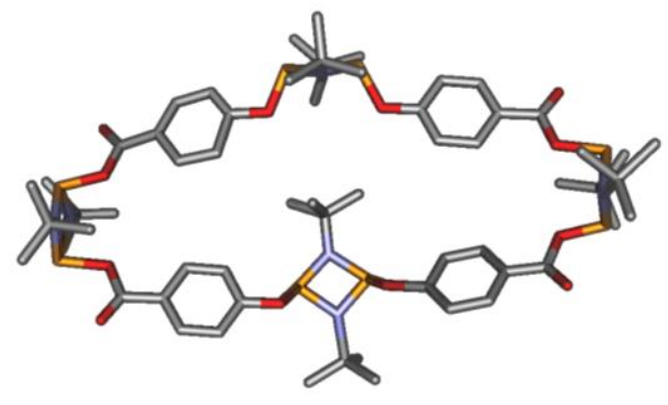

Figure 4. Crystal structures of the two different conformers of cis tetrameric macrocycle (4). 


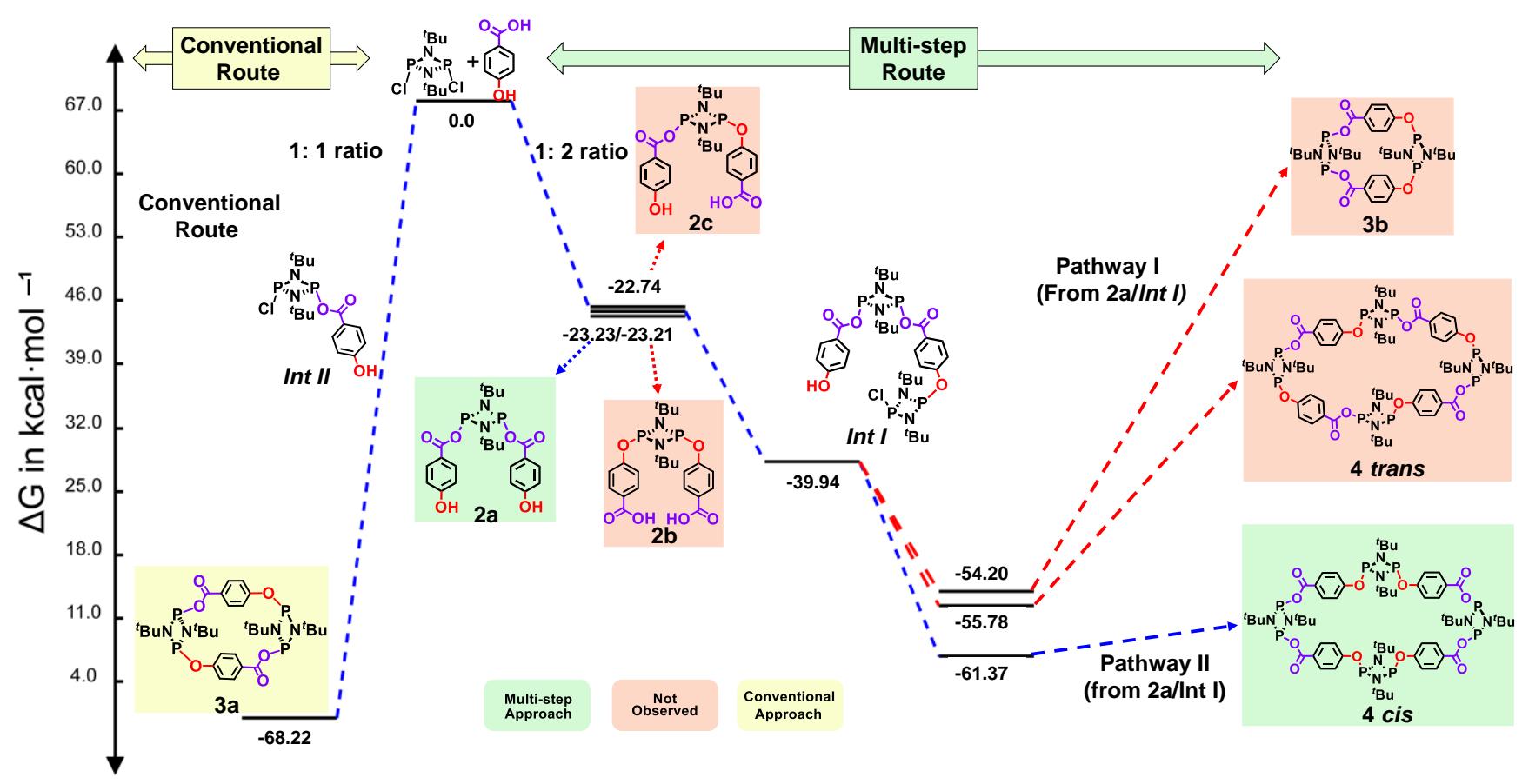

Scheme 2. Relative Gibbs free energy diagram for the formation of the tetrameric macrocycle 4 calculated at the $\omega B 97 \times D / 6-31 G(d, p)$ level of theory

the tetramer $\mathbf{4}$ instead of the dimer $\mathbf{3 b}$. This suggests that the two free hydroxyl groups present in the cis pre-formed building block 2a are too far apart $(\approx 6.0 \AA)$, disabling the cyclic arrangement closure with one dichlorophosphazane unit and in turn resulting in the formation of the tetrameric macrocycle 4 .

The large $d_{\mathbf{o}}$ distance proposed - a crucial structural feature of 2a, - is supported by the previously reported $\left.\left[(\mathrm{CN}) \mathrm{C}_{6} \mathrm{H}_{4}(\mathrm{O}) \mathrm{CO}\right) \mathrm{P}\left(\mu-\mathrm{N}^{t} \mathrm{Bu}\right)\right]_{2 .} .{ }^{\left[{ }^{[35]}\right.}$ In this species, the average separation between the $-X$ substituents on the distal para positions is around $7 \AA$, which is much larger than the separation between the chlorine atoms in the dichloro substituted starting material $1 \quad(4.1 \AA)^{[45]}$ or any other reported dichlorocyclodiphosphazanes (ranging from 3.8 to $4.7 \AA$ ) (See Table S2 SI). ${ }^{[3,44,46-50]}$ Therefore, the subsequent addition of $\mathbf{1}$ resulted in the formation of tetrameric macrocycle 4 via condensation of two molecules of intermediate int I (Scheme 2).

Computational calculations were performed to both rationalise the experimental observations and gain insights into the mechanism involved in the formation of 4 . Firstly, the key role of the pre-arranged rigid monomer $2 \mathrm{a}$ was investigated. To this end, the three possible isomers of the monomer 2 were optimised using density functional theory (DFT). It was found that the most stable isomer is the one where the organic linkers are attached to the phosphazane unit via the acid group (cis-2a, Scheme 2) followed by the isomer in which the organic linkers attached via the alkoxy groups (cis-2b). Finally, the least stable isomer was computed to be trans-2c with one acid group and one alkoxy group directly bonded to the $\mathrm{P}_{2} \mathrm{~N}_{2}$ unit.

This observation is in good agreement with the experimental observations, where only the cis-2a isomer is observed in the insitu ${ }^{31} \mathrm{P}\left\{{ }^{1} \mathrm{H}\right\}$ NMR spectra, due to the higher pKa of the acid group, thus validating our stepwise approach. Once $\mathbf{2 a}$ is formed, it reacts with a 1 to form an asymmetrically substituted monomeric intermediate, $\left[\left(\mathrm{HOC}_{6} \mathrm{H}_{4}(\mathrm{O}) \mathrm{CO}\right)-\left(\mathrm{P}\left(\mu-\mathrm{N}^{\mathrm{B} u} \mathrm{Bu}\right)\right)_{2}-\mathrm{O}(\mathrm{CO}) \mathrm{C}_{6} \mathrm{H}_{4} \mathrm{O}-(\mathrm{P}(\mu-\right.$ $\left.\left.\mathrm{N}^{\mathrm{t} B u}\right)\right)_{2}-\mathrm{Cl}$ (Int I), where a new $\mathrm{P}-\mathrm{O}$ bond has been formed. Once the first $\mathrm{P}-\mathrm{O}$ bond has been formed, there are two possible reaction pathways (see Scheme 2): (i) an intramolecular nucleophilic attack between the $\mathrm{OH}$ moiety and the terminal $\mathrm{P}-\mathrm{Cl}$ within Int I to form a second P-O bond, and hence yielding the cisdimeric macrocycle $\mathbf{3 b}$ (not observed experimentally) (Pathway I in Scheme 2)., (ii) or an intermolecular reaction between two Int I molecules to produce the observed cis-tetrameric macrocycle 4 (Pathway II in Scheme 2).

Within the context of these two possible reaction pathways, int I was optimised, and its most stable configuration displays a $\mathrm{Cl}$ $\mathbf{P}$... OH distance of $6.6 \AA$ indicating a difficult and unlikely nucleophilic attack to form $\mathbf{3 b}$ (Figure S13a). Additionally, a scan of $360^{\circ}$ of the Ph-O-P dihedral angle was carried out in order to find the closest possible $\mathrm{Cl}-\mathrm{P}$... OH distance, which was found to be $4.3 \AA$ (Figure S13a). At more than two-fold the average P-O bond distance observed in phosphazane species this further proves the difficulty of the cis-dimeric macrocycle $3 \mathbf{b}$. ${ }^{[31-33]}$

Alternatively, rotation around the $\mathbf{P}-\mathbf{O}$ bond in int $\mathbf{I}$ could potentially locate the $\mathrm{P}-\mathrm{Cl}$ and $-\mathrm{Ph}-\mathrm{OH}$ terminal moieties close enough for the intramolecular nucleophilic attack required to form 3b to take place. Within this context, an energy scan for the rotation around the $\mathbf{P}-\mathbf{O C}(\mathrm{O}) \mathrm{PhOH}$ bond in $\mathbf{2 a}$ was calculated. The calculated rotation displays a high energy barrier $(\sim 12$ $\mathrm{Kcal} \cdot \mathrm{mol}^{-1}$ ), which is in good accord with the experimentally observed preference for exo,exo configuration displayed by all the previously reported cyclophosphazane species comprising $-p$ $\mathrm{OC}(\mathrm{O})-\mathrm{X}$ moieties. In contrast the $\mathbf{P}-\mathbf{O}$ rotation barrier for then alkoxy derivative $\mathbf{2 b}$ (i.e., the $\mathbf{P}-\mathbf{O P h C}(\mathrm{O}) \mathrm{OH}$ bond) is roughly half $\left(\sim 6 \mathrm{Kcal}^{\circ} \cdot \mathrm{mol}^{-1}\right)$, which is consistent for the exo,endo preference observed this type of species. ${ }^{[31-33]}$ 
Additionally, the cis-and trans-dimeric macrocycles (3a and $\mathbf{3 b}$, respectively) were optimised to rationalise both the observation of the previously reported trans-dimeric macrocycle $\mathbf{3 a}$ as a side product, as well as the failure to observe its cis-dimeric counterpart 3b. Our DFT calculations indicate that $\mathbf{3 a}$ is 14.00 $\mathrm{Kcal} \cdot \mathrm{mol}^{-1}$ more stable than $\mathbf{3 b}$, which is in agreement with the experimentally observed exclusive formation of $\mathbf{3 a}$ from the $1: 1$ reaction of 1 with $p-\mathrm{HOC}(\mathrm{O}) \mathrm{PhOH}$, presumably via the condensation of two Int II molecules (see Scheme 2 left conventional synthetic route). Interestingly, the formation of a small amount of $\mathbf{3 a}$ is observed in the in situ ${ }^{31} \mathrm{P}$ NMR using our approach. This phenomenon can be attributed to a $\mathrm{Cl}^{-}$mediated cleavage of one of the P-O-Ph bonds in $\mathbf{2} \mathbf{b}$, leading to the formation of Int II and the subsequent formation of $\mathbf{3 a}$, which has been previously described for strained phosphazane species. ${ }^{[51]}$

Finally, we computed the energies of both cis and trans isomers of the tetrameric macrocycle 4. The computational calculations indicate that the cis isomer is thermodynamically favoured over its trans counterpart (i.e., $5.59 \mathrm{Kcal}^{\circ} \mathrm{mol}^{-1}$, see Figure S14).

Overall, our theoretical studies suggest that both the strong preference for an exo,exo conformation of the -C(O)O- moieties combined with the stepwise synthetic route used are critical for the successful formation of the tetrameric macrocycle herein reported.

\section{Conclusions}

The proposed novel multi-step synthetic route comprising complex and rationally pre-arranged building blocks has been demonstrated to unlock the synthesis of previously unattainable hybrid inorganic-organic macrocycles.

The herein reported unfolded tetrameric macrocycle displays the largest large cavity area of its kind $\left(110.1 \AA^{2}\right)$ due to the strong exo, exo preference of the building block used, thus preventing the formation of the conventionally obtained exo,endo folded counterparts. With the success in designing a controlled synthetic methodology for macrocycles with large cavity, effort and attention will subsequently be applied towards expanding our approach to a wide range of phosphazane frameworks.

Finally, our work highlights the need to invest further efforts on the synthesis of a wide range topologically rigid complex building blocks across the cyclophosphazane family to access larger macrocyclic frameworks that are able to compete, or even surpass, their organic counterparts in the fields of host-guest and supramolecular chemistry in the race to achieve industrially-ready functional materials and devices solely based on inorganic building blocks.

\section{Acknowledgements}

F. G. would like to thank $A^{*}$ STAR AME IRG (A1783c0003 and A2083c0050), MOE AcRF Tier 1 (M4011709) and NTU startup grant (M4080552) for financial support. F.L. would like to thank A*STAR for fellowship. J.K.C acknowledge the support of the Australian Research Council through DP1901012036. J. D. thanks COMPUTAEX for granting access to LUSITANIA supercomputing facilities.

\section{Author Contributions}

tBoth authors contributed equally to the work
Keywords: phosphazane $\cdot$ macrocycle $\cdot$ hybrid $\cdot$ pre-arrangued - building block

[1] P. Comba, A. Eisenschmidt, L. R. Gahan, G. R. Hanson, N. Mehrkens M. Westphal, Dalton Trans., 2016, 45, 18931-18945.

[2] J. R. Holst, A. Trewin, A. I. Cooper, Nat. Chem., 2010, 2, 915-920.

[3] A. C. Sudik, A. R. Millward, N. W. Ockwig, A. P. Côté, J. Kim, O. M. Yaghi, J. Am. Chem. Soc., 2005, 127, 7110-7118.

[4] Jr. J. Rebek, Chem. Commun., 2000, 637-643.

[5] F. García, R. A. Kowenicki, I. Kuzu, M. McPartlin, L. Riera, D. S. Wright, Inorg. Chem. Commun., 2005, 8, 1060-1062.

[6] F. García, J. M. Goodman, R. A. Kowenicki, I. Kuzu, M. McPartlin, M. A. Silva, L. Riera, A. D. Woods, D. S. Wright, Chem. Eur. J., 2004, 10, 6066-6072.

[7] S. G. Calera, D. S. Wright, Dalton Trans., 2010, 39, 5055-5065.

[8] A. J. Plajer, R. Garcia-Rodriguez, C. G. M. Benson, P. D. Matthews, A. D. Bond, S. Singh, L. H. Gade, D. S. Wright, Angew. Chem. Int. Ed., 2017, 56, 9087--9090.

[9] H. Niu, A. J. Plajer, R. Garcia-Rodriguez, S. Singh, D. S. Wright, Chem Eur. J., 2018, 24, 3073-3082.

[10] A. D. Bond, E. L. Doyle, F. García, R. A. Kowenicki, M. McPartlin, L. Riera, D. S. Wright, Chem. Commun., 2003, 0, 2990-2991.

[11] A. Bashall, A. D. Bond, E. L. Doyle, F. García, S. Kidd, G. T. Lawson, M. C. Parry, M. McPartlin, A. D. Woods, D. S. Wright, Chem Eur. J., 2002, 8, 3377-3385.

[12] H. Klare, S. Hanft, J. M. Neudorfl, N. E. Schlorer, A. Griesbeck, B Goldfuss, Chem. Eur. J., 2014, 20, 11847--11855.

[13] F. F. Wolf, J. M. Neudorfl, B. Goldfuss, New J. Chem., 2018, 42, 4854-4870.

[14] X. Shi, F. León, Y. Sim, S. Quek, G. Hum, Y. X. J. Khoo, Z. X. Ng, M. Y. Par, H. C. Ong, V. K. Singh, R. Ganguly, J. K. Clegg, J. Díaz, F. García, Angew. Chem. Int. Ed., 2020, 59, 22100-22108.

[15] M. S. Balakrishna, Dalton Trans., 2016, 45, 12252-82.

[16] M. S. Balakrishna, R. V. Sreenivasa, S. S. Krishnamurthy, J. F. Nixon, J. C. T. R. B. S. St. Laurent, Coord. Chem. Rev., 1994, 129, 1--90.

[17] G. S. Ananthnag, J. T. Mague, M. S. Balakrishna, J. Organomet. Chem. 2015, 779, 45--54.

[18] G. S. Ananthnag, J. T. Mague, M. S. Balakrishna, Dalton Trans., 2015 44, 3785--3793.

[19] M. S. Balakrishna, Phosphorus Sulfur Silicon Relat. Elements, 2016, 191, 567--571.

[20] M. E. Otang, D. Josephson, T. Duppong, L. Stahl, Dalton Trans., 2018 47, 11625--11635.

[21] M. E. Otang, G. R. Lief, L. Stahl, J. Organomet. Chem., 2016, 820, 98110.

[22] G. R. Lief, D. F. Moser, L. Stahl, R. J. Staples, J. Organomet. Chem., 2004, 689, 1110--1121.

[23] L. Grocholl, L. Stahl, R. J. Staples, Chem. Commun., 1997, 2, 1465-1466.

[24] D. Suresh, M. S. Balakrishna, K. Rathinasamy, D. Panda, S. M. Mobin, Dalton Trans., 2008, 21, 2812--2814.

[25] D. Suresh, M. S. Balakrishna, J. T. Mague, Dalton Trans., 2008, 3272-3274

[26] A. Rashid, G. S. Ananthnag, S. Naik, J. T. Mague, D. Panda, M. S. Balakrishna, Dalton Trans., 2014, 43, 11339--11351.

[27] D. Tan, Z. X. Ng, Y. Sim, R. Ganguly, F. Garcia, Crystengcomm, 2018, 20, 5998--6004.

[28] A. J. Plajer, J. Zhu, P. Prohm, F. J. Rizzuto, U. F. Keyser, D. S. Wright, J. Am. Chem. Soc., 2020, 142, 1029--1037.

[29] A. J. Plajer, J. Zhu, P. Proehm, A. D. Bond, U. F. Keyser, D. S. Wright, J. Am. Chem. Soc., 2019, 141, 8807--8815.

[30] A. J. Plajer, F. J. Rizzuto, H. C. Niu, S. Lee, J. M. Goodman, D. S. Wright, Angew. Chem. Int. Ed., 2019, 58, 10655--10659.

[31] H. Klare, J. M. Neudorfl, B. Goldfuss, Beilstein J. Org. Chem., 2014, 10, 224--236.

[32] X. Shi, F. León, H. C. Ong, R. Ganguly, J. Díaz, d, F. García, Comms Chem., 2021, DOI: 10.1038/s42004-021-00455-9 
[33] G. S. Ananthnag, S. Kuntavalli, J. T. Mague, M. S. Balakrishna, Inorg. Chem., 2012, 51, 5919--5930.

[34] F. Dodds, F. Garcia, R. A. Kowenicki, S. P. Parsons, M. McPartlin, D. S. Wright, Dalton Trans., 2006, 2, 4235--4243.

[35] Y. Sim, Y. X. Shi, R. Ganguly, Y. Li, F. Garcia, Chem Eur. J., 2017, 23, 11279--11285.

[36] V. S. Kashid, J. T. Mague, M. S. Balakrishna, J. Chem. Sci., 2017, 129, 1531--1537.

[37] F. Garcia, R. A. Kowenicki, I. Kuzu, L. Riera, M. McPartlin, D. S. Wright, Dalton Trans., 2004, 7, 2904--2909.

[38] F. Garcia, J. M. Goodman, R. A. Kowenicki, M. McPartlin, L. Riera, M. A Silva, A. Wirsing, D. S. Wright, Dalton Trans., 2005, 1764-1773

[39] F. Dodds, F. Garcia, R. A. Kowenicki, M. McPartlin, A. Steiner, D. S. Wright, Chem. Commun., 2005, 3733--3735.

[40] F. Dodds, F. Garcia, R. A. Kowenicki, M. McPartlin, L. Riera, A. Steiner, D. S. Wright, Chem. Commun., 2005, 1, 5041--5043.

[41] A. Brückner, A. Hinz, J. B. Priebe, A. Schulz, A. Villinger, Angew. Chem. Int. Ed., 2015, 54, 7426-7430.

[42] W. A. Kamil, M. R. Bond, J. M. Shreeve, Inorg. Chem., 1987, 26, 20152016.

[43] M. S. Balakrishna, R. Venkateswaran, J. T. Mague, Dalton Trans., 2010, 39, 11149-11162.

[44] T. Roth, H. Wadepohl, D. S. Wright, L. H. Gade, Chem. Eur. J., 2013, 19, 13823-13837.

[45] K. W. Muir, J. Chem. Soc., Dalton Trans., 1975, 0, 259-262.

[46] A. Schulz, A. Villinger, A. Westenkirchner, Inorg. Chem., 2013, 52, 11457-11468

[47] A. L. Brazeau, M. M. Hänninen, H. M. Tuononen, N. D. Jones, P. J. Ragogna, J. Am. Chem. Soc., 2012, 134, 5398-5414.

[48] H. J. Chen, R. C. Haltiwanger, T. G. Hill, M. L. Thompson, D. E. Coons, A. D. Norman, Inorg. Chem., 1985, 24, 4725-4730.

[49] M. Kuprat, M. Lehmann, A. Schulz, A. Villinger, Inorg. Chem., 2011, 50, 5784-5792.

[50] A. Bashall, E. L. Doyle, F. García, G. T. Lawson, D. J. Linton, D. Moncrieff, M. McPartlin, A. D. Woods, D. S. Wright, Chem. Eur. J., 2002, 8, 57235731.

[51] T. Roth, V. Vasilenko, H. Wadepohl, D. S. Wright, L. H. Gade, Inorg Chem., 2015, 54, 7636--7644. 
